Polymer Journal, Vol. 5, No. 3, pp 263-267 (1973)

\title{
X-ray Study on the Thermal Expansion of Cotton Cellulose
}

\author{
Sulo Seitsonen and Ilkka Mikkonen* \\ Department of Physics 2, University of Turku, Turku, Finland.
}

(Received April 17, 1973)

\begin{abstract}
The thermal expansion of cotton cellulose was studied. The 101, 101, and 002 spacings were measured at 28 different temperatures from $-151{ }^{\circ} \mathrm{C}$ to $232^{\circ} \mathrm{C}$. It was found that only for the 002 spacings could enough accuracy be attained to calculate the coefficients of thermal expansion. A curve of the coefficient of thermal expansion for the 002 spacing vs. temperature was obtained.
\end{abstract}

KEY WORDS X-ray / Thermal Expansion / Cellulose / Cotton /

It is known that the unit cell of native cellulose is monoclinic, with these dimensions at room temperature: $a=8.35 \AA, b=10.3 \AA, c=$ $7.9 \AA$, and $\beta=84^{\circ}$. The direction of the $b$ axis is the chain direction of the cellulose molecules. It must be noted that the planes of the glucose units are parallel to the (002) crystallographic planes which contain the $b$ axis direction.

An early X-ray study by Hengstenberg and Mark $^{1}$ gives some experimental data on the thermal expansion of ramie cellulose. These authors measured the average coefficient of thermal expansion between liquid air and room temperatures. They obtained $\rho_{001}=(0.6 \pm 0.1) \times$ $10^{-4 \circ} \mathrm{C}^{-1}$ and $\rho_{010}=(-0.2 \pm 0.2) \times 10^{-4 \circ} \mathrm{C}^{-1}$. One can see that the possible errors were quite large in spite of the wide temperature range used in the study. This was partly due to the significant width of the diffraction lines, which made the determination of their exact positions rather inaccurate. Another cause reducing the accuracy of the X-ray measurements was the fact that the observable diffraction lines of cellulose occur at relatively low angles. Wakelin, Sutherland, and $\mathrm{Beck}^{2}$ measured the average thermal expansion coefficients of cotton cellulose between -196 and $+20^{\circ} \mathrm{C}$. They obtained $\alpha_{\mathrm{a}}=60 \times$ $10^{-6}{ }^{\circ} \mathrm{C}^{-1}, \quad \alpha_{\mathrm{c}}=28 \times 10^{-6}{ }^{\circ} \mathrm{C}^{-1}, \quad$ and $\alpha_{\mathrm{b}}=-45 \times$ $10^{-6 \circ} \mathrm{C}^{-1}$.

The aim of the present study was to obtain more detailed data on the thermal expansion of cellulose than those given by the above-mentioned authors. In the present study the thermal

\footnotetext{
* Present address: Outokumpu Oy, Pori, Finland.
}

expansion was studied over a temperature range from $-151^{\circ} \mathrm{C}$ to $232^{\circ} \mathrm{C}$. The specimen was a bundle of parallel native cotton fibers.

\section{EQUIPMENT}

The measurements at temperatures from $-151^{\circ} \mathrm{C}$ to $10^{\circ} \mathrm{C}$ were performed by using liquid air to cool the nitrogen gas flow in which the fiber bundle was kept during X-ray exposures. Figure 1 shows the apparatus used to regulate the temperature of the flow. The flow of nitrogen coming from the gas container through a pressure-lowering ventilator was divided into two tubes. The upper tube was at room temperature. The lower, coiled tube was sunk in liquid air. The flows from these two tubes were mixed. The relative amounts of cooled and non-cooled nitrogen were regulated by the two ventilators shown in the figure.

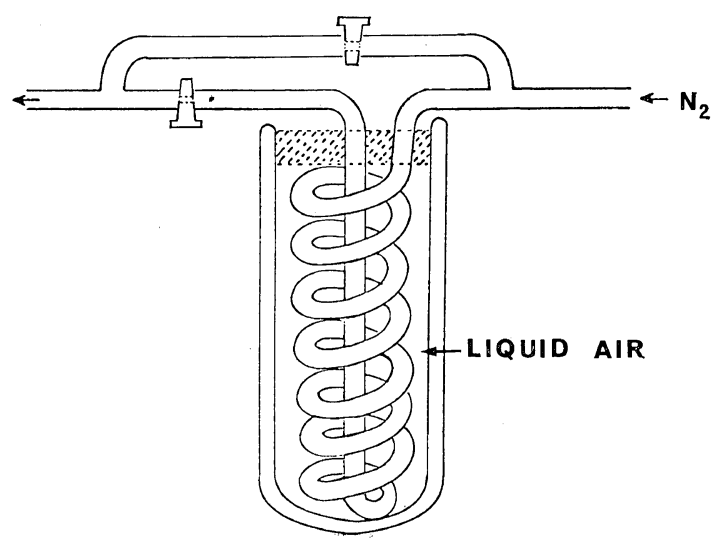

Figure 1. Apparatus for temperature regulation. 


\section{S. Seitsonen and I. Mikkonen}

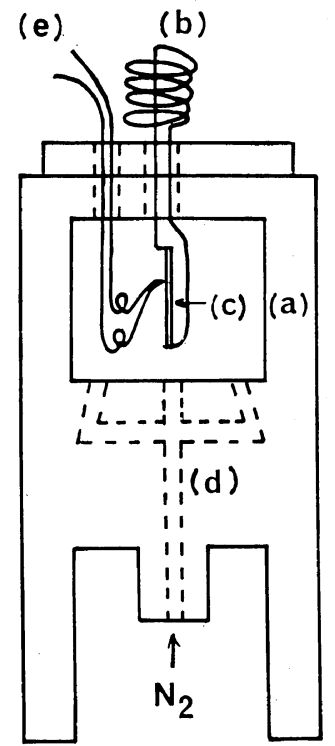

Figure 2. Specimen holder.

The temperature of the specimen was decreased to the value desired. This could be done in about $5 \mathrm{~min}$. Then the velocity of the gas flow was regulated to maintain a constant temperature. The temperature was checked during the measurement. It was possible to keep the temperature of the specimen constant within $\pm 4^{\circ} \mathrm{C}$ even at $-150^{\circ} \mathrm{C}$ by using this arrangement.

Figure 2 shows the specimen holder. The frame (a) was made of an acryl plate of about $10 \mathrm{~mm}$ in thickness. A metal coil (b) was used to strain the fiber bundle (c). On both sides of the frame plate cellophane films were glued to guide the flow of cold nitrogen around the specimen. The gas flowed into the specimen holder from below through the 3 holes branching from the hole (d). The gas flowed out of the specimen holder through the round holes made in the cellophane films for the primary X-ray beam. A copperconstantan thermoelement (e) was used to measure the temperature of the specimen.

A flat photographic film was placed in a cassette behind the specimen perpendicular to the primary X-ray beam at a distance of about $37 \mathrm{~mm}$ from the specimen. The specimen and photographic film were in a camera box. The length and diameter of the pinhole were 75 and $0.5 \mathrm{~mm}$, respectively.

The X-ray measurements at temperatures higher than room temperature were performed using a Rigaku-Denki high-temperature camera. The temperature of the cellulose specimen was determined from the thermal expansion of gold. For this purpose a little gold powder was put into the $0.5-\mathrm{mm}$ glass capillary used as the specimen holder together with the cotton fibers. The diffraction lines of gold were thus obtained on the same film as those of the cellulose. The unsymmetrical or Straumanis method ${ }^{3}$ of film loading was used. Systematic errors in the measurement of the lattice parameters of gold were eliminated by using the Nelson-Riley extrapolation function. ${ }^{3}$ To obtain sharp diffraction lines the filed gold powder was heated to $400^{\circ} \mathrm{C}$ and then cooled slowly. Ni-filtered $\mathrm{CuK} \alpha$ radiation of $44 \mathrm{kV}$ and $15 \mathrm{~mA}$ was used. The exposure times were $30 \mathrm{~min}$ and $3 \mathrm{hr}$ for low and high temperature photographs, respectively. Ilford Ilfex X-ray film was used.

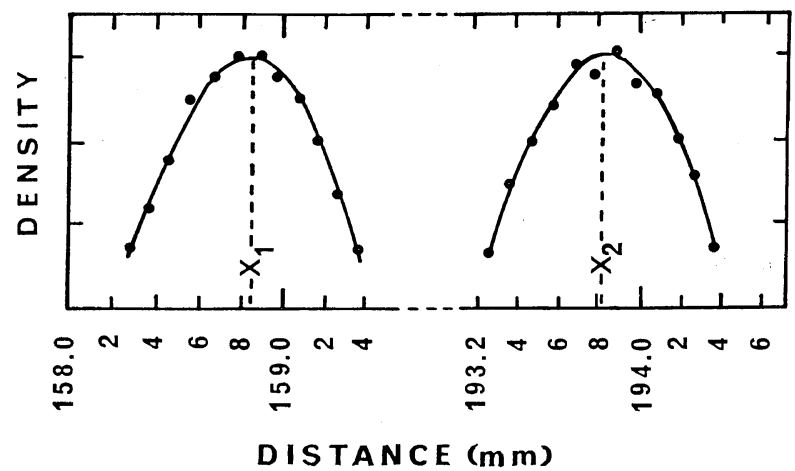

Figure 3. Determination of the positions $x_{1}$ and $x_{2}$ of the 002 diffraction lines. The photographic density is given in arbitrary units. 


\section{Determination of the Positions of the Diffraction Lines}

The diffraction lines of cellulose are, for example very broad compared with those of metals. The determination of the positions of the lines of cellulose is, therefore, not as easy as in the case of sharp diffraction peaks. The distance on the film between the 002 reflections on both sides of the primary beam was measured with the help of a Jaco microphotometer. The film was moved in steps of $0.1 \mathrm{~mm}$. The readings of the mirror galvanometer of the photometer were plotted as a function of the position on the film. With a stencil it was possible to draw curves of the same shape through the plots for various peak maxima. The positions of the maxima of these curves were used as the positions of the lines (Figure 3).

\section{MEASUREMENTS AND RESULTS}

\section{High Temperature Measurements}

Eight exposures were made on the same film

Table I. Lattice parameters a of gold powder and the corresponding temperatures $t$

\begin{tabular}{ccccccc}
\hline \multirow{2}{*}{ Exposure } & \multicolumn{2}{c}{ Film 1} & & \multicolumn{2}{c}{ Film 2} \\
\cline { 2 - 3 } \cline { 5 - 6 } & $a, \AA$ & $t,{ }^{\circ} \mathrm{C}$ & & $a, \AA$ & $t,{ }^{\circ} \mathrm{C}$ \\
\hline 1 & 4.0782 & 18 & & 4.0778 & 11 \\
2 & 4.0806 & 62 & & 4.0798 & 47 \\
3 & 4.0826 & 97 & & 4.0814 & 76 \\
4 & 4.0846 & 131 & & 4.0832 & 107 \\
5 & 4.0874 & 178 & & 4.0855 & 146 \\
6 & 4.0888 & 201 & & 4.0875 & 180 \\
7 & 4.0899 & 219 & & 4.0883 & 193 \\
8 & & & & 4.0907 & 232 \\
\hline
\end{tabular}

Table II. Spacing $d_{002}$ of cotton cellulose at various temperatures $t$

\begin{tabular}{rcccc}
\hline \multicolumn{2}{c}{ Film 1} & & \multicolumn{2}{c}{ Film 2} \\
\cline { 1 - 2 } \cline { 5 - 5 }$t,{ }^{\circ} \mathrm{C}$ & $d_{002}, \AA$ & & $t_{0}^{\circ} \mathrm{C}$ & $d_{002}, \AA$ \\
\hline 18 & 3.923 & & 11 & 3.887 \\
62 & 3.913 & & 47 & 3.900 \\
97 & 3.924 & & 76 & 3.930 \\
131 & 3.939 & & 107 & 3.919 \\
178 & 3.959 & & 146 & 3.939 \\
201 & 3.983 & & 180 & 3.957 \\
219 & 4.006 & & 193 & 3.971 \\
& & & 232 & 4.010 \\
\hline
\end{tabular}

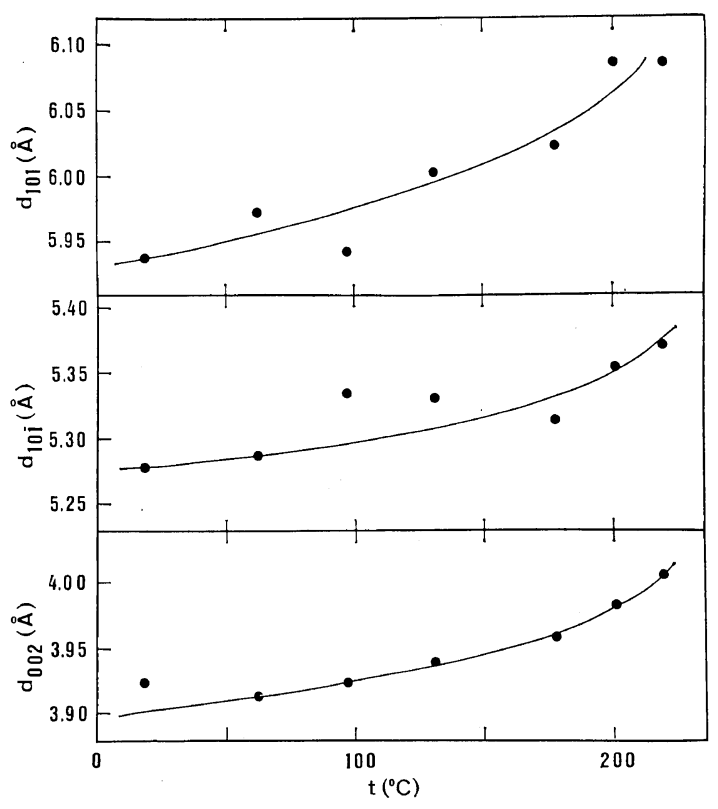

Figure 4. The spacings $d_{101}, d_{101}$, and $d_{002}$ of cotton cellulose at various temperatures $t$.

at various temperatures between room temperature and $232^{\circ} \mathrm{C}$. Two different films were used. Table I shows the measured lattice parameters of gold and the corresponding temperatures. Table II gives the $d_{002}$ values at various temperatures.

We also performed measurements of the spacings $d_{101}$ and $d_{10 \overline{1}}$. Figure 4 shows the $d_{002}$, $d_{10 \overline{1}}$, and $d_{101}$ values obtained from Film 1 . The determination of the positions of the 101 and $10 \overline{1}$ diffraction lines was less accurate than that of the 002 lines.

\section{Low-Temperature Measurements}

The specimen was not moved between different exposures. The distance between the specimen and film was determined with the help of the $2 \theta$ value measured by the high-temperature camera at $+26^{\circ} \mathrm{C}$. It was presumed that this distance remained constant during the different exposures.

Table III shows the results for various temperatures measured by the thermocouple, with the observed fluctuations.

Coefficient of Thermal Expansion of 002 Spacing

Figure 5 shows the spacing $d_{002} v s$. temperature, following Table II and III. A graphically 
Table III. Spacing $d_{002}$ of cotton cellulose at various temperatures $t$

\begin{tabular}{ccc}
\hline Film & \multicolumn{1}{c}{$t,{ }^{\circ} \mathrm{C}$} & $d_{002}, \AA$ \\
\hline 3 & $+26 \pm 0.5$ & 3.893 \\
4 & $+10 \pm 2$ & 3.892 \\
5 & $-5 \pm 2$ & 3.879 \\
6 & $-20 \pm 4$ & 3.883 \\
7 & $-30 \pm 3$ & 3.880 \\
8 & $-40 \pm 1$ & 3.882 \\
9 & $-51 \pm 1$ & 3.878 \\
10 & $-61 \pm 2$ & 3.873 \\
11 & $-72 \pm 2$ & 3.866 \\
12 & $-81 \pm 2$ & 3.864 \\
13 & $-91 \pm 1$ & 3.862 \\
14 & $-131 \pm 2$ & 3.850 \\
15 & $-151 \pm 2$ & 3.842 \\
\hline
\end{tabular}

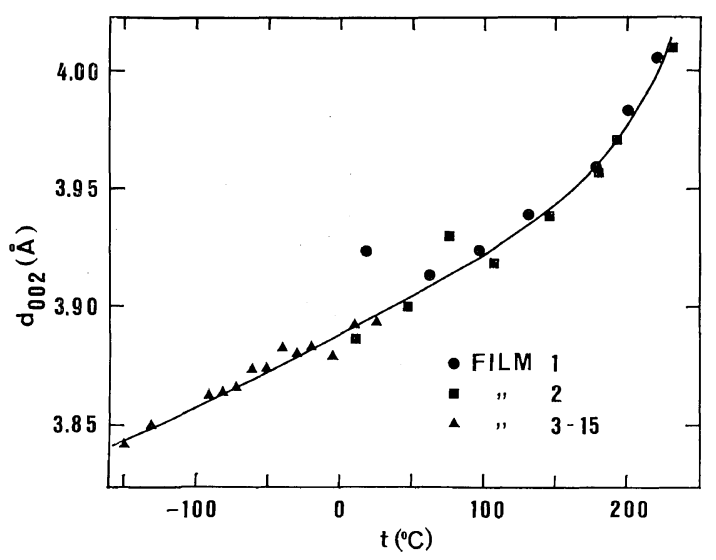

Figure 5. Spacing $d_{002}$ of cotton cellulose $v s$. temperature.

smoothed curve was drawn through the experimental points. Using this curve the coefficients of thermal expansion at various temperatures were determined by the formula

$$
\alpha=\frac{1}{d_{002}} \frac{\Delta d_{002}}{\Delta t} .
$$

Table IV and Figure 6 show the variation of $\alpha$ vs. $t$.

\section{DISCUSSION}

It is known that the relative error of a measured spacing $d$ can be expressed as

$$
\Delta d / d=-\cot \theta \Delta \theta
$$

Table IV. Coefficient $\alpha$ of the thermal expansion of the spacing $d_{002}$ of cotton cellulose at various temperatures $t$

\begin{tabular}{rccc}
\hline$t,{ }^{\circ} \mathrm{C}$ & $\alpha \times 10^{5}, 1 /{ }^{\circ} \mathrm{C}$ & $t,{ }^{\circ} \mathrm{C}$ & $\alpha \times 10^{5}, 1 /{ }^{\circ} \mathrm{C}$ \\
\hline-150 & 7.1 & 50 & 8.7 \\
-125 & 7.2 & 75 & 9.0 \\
-100 & 7.4 & 100 & 9.6 \\
-75 & 7.6 & 125 & 10.7 \\
-50 & 7.7 & 150 & 12.0 \\
-25 & 7.8 & 175 & 16.0 \\
0 & 8.0 & 200 & 25.0 \\
25 & 8.2 & 225 & 36.7 \\
\hline
\end{tabular}

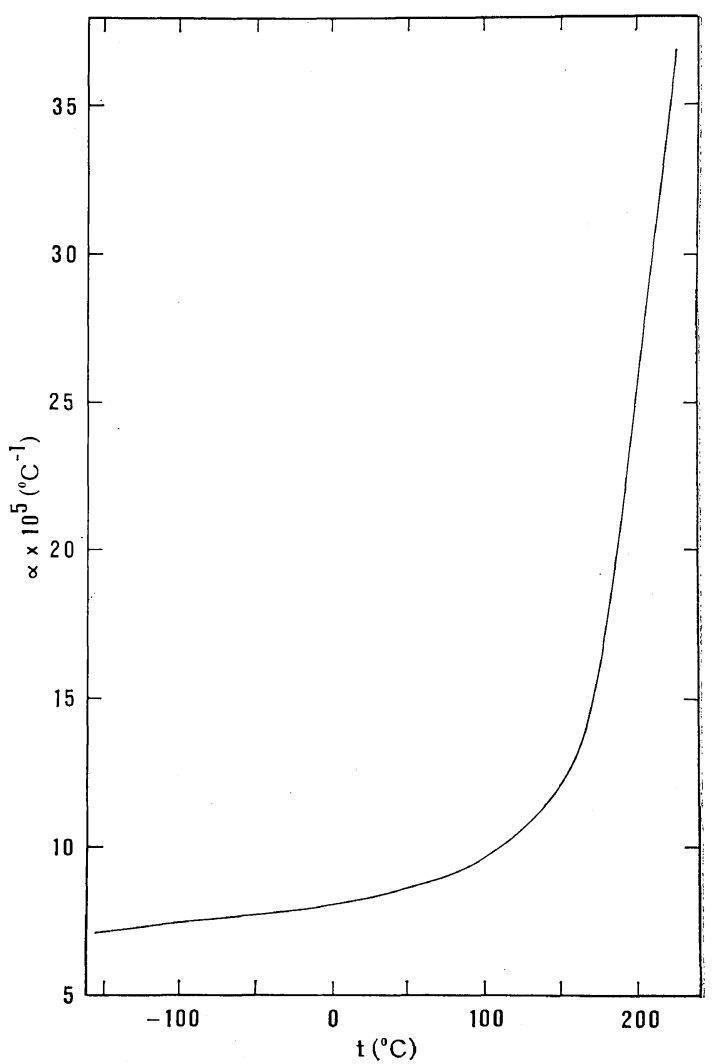

Figure 6. Graph showing the coefficient of thermal expansion of the 002 spacing $v s$. temperature for cotton cellulose.

Because in our measurements the $\theta$ angle was relatively small, the relative error $\Delta d / d$ due to the measurement of the $\theta$ angle is, according to eq 2, quite large. Supposing that the error of the measurement of the line position is $<0.04 \mathrm{~mm}$, 
we obtain for a spacing of $4 \AA$ an error $<0.01 \AA$, when the radius of the camera is $45 \mathrm{~mm}$. This error can be also used for our low temperature camera. Supposing that the fluctuation in the measured temperatures is $<7^{\circ} \mathrm{C}$, we find from Figure 5 the error of $d_{002}$ due to temperature measurement to be $<0.003 \AA$ for temperatures $<50^{\circ} \mathrm{C}$ and $<0.012 \AA$ for temperatures $>50^{\circ} \mathrm{C}$. We have then total errors of $<0.013 \AA$ and $<0.022 \AA$ for $d_{002}$ at temperatures $<50^{\circ} \mathrm{C}$ and $>50^{\circ} \mathrm{C}$, respectively. These errors do not contain systematic errors and thus show only the limits for deviations from the smoothed curve in Figure 5. Systematic errors in the $d_{002}$ values do not, however, have any significant effect on the determination of $\alpha$, because we can suppose that all the $d_{002}$ values contain approximately equal systematic errors. Therefore, systematic errors do not affect the values of the slope of the curve for $d_{002} v s . t$. Eq 1 shows that the relative errors of $d_{002}$ and of the slope determine the error of $\alpha$. The relative error of $d_{002}$ is, however, very small compared with that of the slope.

If we assume that the actual curve of $d_{002} v s$. temperature does not show greater local curvatures than the curve in Figure 5, the relative error of $\alpha$ at temperatures lower than $50^{\circ} \mathrm{C}$ can be estimated to be less than $15 \%$. The possible error increases with increasing temperature and may be as much as $45 \%$ at $200^{\circ} \mathrm{C}$.

It can be seen from the curves in Figures 5 and 6 that the thermal expansion of $d_{002}$ is relatively strong over the whole temperature range studied. This is a natural consequence of the weakness of the forces between the chain molecules. The coefficient $\alpha$ seems to grow almost linearly at low temperatures. At temperatures above $100^{\circ} \mathrm{C}$ a very strong non-linear growth of $\alpha$ takes place. One can state that the average coefficient measured by Hengstenberg and Mark (see Introduction) is in agreement with our results within the limits of experimental error. The $\alpha_{\mathrm{c}}$ value of Wakelin, et al., however, is distinctly smaller than our $\alpha$ values in the corresponding temperature region.

Acknowledgment. The authors wish to record their thanks to Professor Martti Kantola for his interest and for extending the facilities of the laboratory.

\section{REFERENCES}

1. J. Hengstenberg and H. Mark, Z. Krist., 69, 271 (1928).

2. J. H. Wakelin, A. Sutherland, and L. R. Beck, J. Polym. Sci., 42, 278 (1960).

3. A. Taylor, "X-ray Metallography", John Wiley \& Sons, Inc., New York, N.Y., 1961. 